\title{
PRAÇA SANT'ANNA: UM PATRIMÔNIO CULTURAL PROTEGIDO PELA AÇÃO CIVIL PÚBLICA (LEI № 7347/85)
}

\author{
SANT'ANNA SQUARE: A CULTURAL PATRIMONY PROTECTED BY PUBLIC \\ CIVIL ACTION (LAW No 7347/85)
}

\section{J. M. P. SILVEIRA ${ }^{1, *}$}

${ }^{1}$ Mestre em História Social (USS). Docente na Faculdade de Santo Antônio de Pádua/RJ (FASAP) e Professor da SEE/RJ e SEE/MG.

\author{
ART ICLE INFO \\ Article history: \\ Received 2018-04-13 \\ Accepted 2018-04-30 \\ Available online 2018-05-30 \\ *Autor correspondente: \\ E-mail:maurinhopires@gmail.com
}

Palavras-chave: Ação Civil Pública. Patrimônio Cultural. Praça Sant'Anna.

Keywords: Civil Class Action. Cultural Patrimony. Sant'Anna Square.

RESUMO: $O$ presente artigo tem por objetivo analisar a importância da Ação Civil Pública (Lei 7.347/85) como instrumento processual de propositura do Ministério Público para a proteção do patrimônio cultural, em particular no que se refere à Praça Sant'Anna, marco central da origem do município de Pirapetinga, no Sul da Zona da Mata de Minas Gerais. Buscou-se identificar os bens culturais de uma coletividade e compreender como a preservação do patrimônio cultural é fundamental para o resgate da memória coletiva de um povo num determinado lugar. A coleta de dados deu-se através da análise dos autos do Processo MPMG-0511.10.000011-2 de instauração da Ação Civil Pública movida pelo Ministério Público Estadual e pela revisão de bibliografias que trata dos fundamentos teóricos que abarcam os conceitos de ação civil pública, patrimônio cultural e memória coletiva. Os resultados revelaram que a Ação Civil Pública foi um relevante instrumento jurídico de defesa da Praça Sant’Anna como um patrimônio cultural a ser preservado.

ABSTRACT: The present article aims to analyze the importance of Public Civil Action (Law 7.347 / 85) as a procedural instrument of the Public Prosecutor for the protection of cultural patrimony in particular the Sant'Anna Square, central landmark origin of the municipality of Pirapetinga in the (Southern Forest Zone of) Sul da Zona da Mata de Minas Gerais. It seeks to identify the cultural assets of a community and understand how the preservation of cultural heritage is critical to the recovery of the collective memory of a people in a particular place. The collection of data took place through the analysis of the records of the process MPMG - 0511.10.00011-2 of instituting the public civil action filed by the state public prosecutor and the revision of bibliographies that deals with the theorical foundations yhat encompass the concepts of public civil action, cultural heritage and collective memory. The results revealed that the public civil action. Was a relevant legal instrument to defend Sant'Anna Square as a cultural heritage to be preserved.

\section{INTRODUÇÃO}

Ao completar 20 anos, a Lei 7347/85 que regulamenta a ação civil pública ainda é desconhecida por muitos como um instrumento de proteção dos interesses transindividuais, isto é, de grupo, classe ou categoria de pessoas. Aliás, em se tratando de direitos coletivos, vale ressaltar que, até a década de 80 , havia uma incompleta legislação processual voltada para a normatização da tutela coletiva, especialmente nas áreas como meio ambiente, patrimônio cultural e direito do consumidor. (FERNANDES, 2013). No entanto, como o acesso à justiça é um pressuposto 
fundamental para o exercício das garantias individuais e coletivas no Estado Democrático, mas que, nem sempre, é efetivamente possível para todos, principalmente para os pobres, busca-se, pelo órgão do Ministério Público, a defesa dos interesses individuais e das associações civis junto ao Poder Judiciário, atribuindo-se ao mesmo órgão a propositura de qualquer ação civil.

Neste contexto, este estudo objetiva compreender a importância da Ação Civil Pública promovida pelo Ministério Público, em particular a que foi instaurada em defesa da preservação da Praça Sant'Anna, um relevante patrimônio histórico e cultural do município de Pirapetinga/MG. Para atingir este objetivo, foi feita uma pesquisa qualitativa, apoiada na análise dos autos do Processo MPMG-0511.10.000011-2 de instauração da Ação Civil Pública movida pelo Ministério Público Estadual, bem como uma revisão bibliográfica acerca dos conceitos relacionados ao tema.

O artigo está organizado em quatro seções posteriores a esta introdução. Na primeira seção, são apresentados os conceitos de ação civil pública e, em particular, faz-se a análise dos autos do Processo MPMG-0511.10.000011-2 de instauração da Ação Civil Pública movida pelo Ministério Público Estadual, que promoveu a tutela da Praça Sant'Anna. Na segunda seção, são apresentados alguns conceitos sobre patrimônio cultural, identificando a sua importância para a vida social. $\mathrm{Na}$ terceira seção, é apresentada uma breve história da Praça Sant'Anna, como sendo marco referencial de Pirapetinga/MG. Por último, são feitas algumas considerações sobre as informações coletadas, destacando a ação civil pública como um hábil instrumento processual de defesa dos interesses difusos.

\section{AÇÃO CIVIL PÚBLICA: DEFINIÇÃO E NATUREZA}

Sabe-se que é o Ministério Público da União e dos Estados o órgão que tem a legitimidade para propor a Ação Civil Pública. Posiciona-se Hugo Nigro Mazzini: "A rigor, sob o aspecto doutrinário, ação civil pública é a ação de objeto não penal proposta pelo Ministério Público" (MANCUSO, 2009, 21).

A propósito, cabe esclarecer que o Ministério Público é uma instituição pública autônoma, a quem a Constituição Federal atribuiu a incumbência de defender a ordem jurídica, o regime democrático e os interesses sociais e individuais indisponíveis. Isto é, o Ministério Público sendo um órgão do Estado, é o grande defensor dos interesses do conjunto da sociedade brasileira. Tem a obrigação, portanto, de defender o interesse público, conduzindo-se, sempre, com isenção, apartidarismo e profissionalismo.

Independente e autônomo, o Ministério Público tem orçamento, carreira e administração próprios. Integram esse órgão os promotores de Justiça (que atuam no primeiro grau de jurisdição) e os procuradores de Justiça (que atuam no segundo grau de jurisdição, junto aos tribunais), auxiliados por servidores, assistentes jurídicos e estagiários.

Considerado o fiscal das leis, o Ministério Público (MP) é o órgão que atua como defensor do povo, tendo o papel de defender o patrimônio nacional, o patrimônio público e social. O que inclui o patrimônio cultural, o meio ambiente, os direitos e interesses da coletividade, especialmente das comunidades indígenas, a família, a criança, o adolescente e o idoso.

Registre-se, que foi o Ministério Público quem promoveu a Ação Civil Pública em defesa da Praça Sant'Anna, por meio de denúncia, ao considera-la, no objeto de propositura, um bem de valor 
socialmente relevante à sociedade pirapetinguense como um todo. Embora haja uma discussão doutrinária em relação à caracterização da Ação Civil Pública, ela pode ser definida como uma ação de caráter público proposta pelo Ministério Público, instituída pela Lei n. 7.347, de 24 de julho de 1985, e consagrada pelo art. 129, III, da Constituição de 1988.

Constitui-se como objeto da Ação Civil Pública a defesa do meio ambiente, dos consumidores, do patrimônio cultural (bens e valores artísticos, estéticos, históricos, turísticos, paisagísticos, etc.), da ordem econômica e da economia popular, da ordem urbanística e de qualquer outro interesse difuso, coletivo ou individual homogêneo. Ainda como objeto desta ação, podemos acrescentar a defesa coletiva das pessoas portadoras de deficiência (Lei n. 7.853/89), dos investidores do mercado de valores mobiliários (Lei n. 7.913/89), das crianças e adolescentes (ECA, art. 210, V), Código de Defesa do Consumidor (8.078/90), dos idosos (Lei n. 10.741/03), entre outros.

Em relação à sua natureza jurídica, constata-se através do trabalho doutrinário de Rodolfo de Camargo Mancuso (2009, p.29) que "a Lei 7.347/85 é predominantemente processual, visto que, basicamente, objetiva oferecer os instrumentos processuais hábeis à efetivação, em juízo, da tutela dos interesses difusos reconhecidos nos textos substantivos." Portanto, trata-se de uma ação "nãopenal”, pois se processa perante o juízo cível e é pública porque defende o patrimônio público, bem como os direitos difusos e coletivos, seguidos dos direitos individuais homogêneos.

Entende-se por direitos difusos aqueles que tratam do interesse de uma categoria, sendo caracterizados principalmente por sua indivisibilidade, onde a satisfação do direito deve atingir a uma coletividade indeterminada, porém, ligada por uma circunstância de fato, cujos prejuízos de uma eventual reparação de dano não podem ser individualmente calculados, como o meio ambiente de uma região.

Os direitos coletivos, em stricto sensu, são aqueles titularizados por pessoas determináveis, compartilhados na mesma relação jurídica indivisível. Por exemplo, se uma ação coletiva de associação de pais e alunos, pleiteando redução das mensalidades, for julgada procedente, todos os pais não associados também receberão tal benefício.

E os direitos individuais homogêneos, são aqueles que decorrem de uma origem comum, possuem transindividualidade instrumental ou artificial, os seus titulares são pessoas determinadas e o seu objeto é divisível e admite reparabilidade direta, ou seja, fruição e recomposição individual, como no caso de reparação por um alimento que gerou a intoxicação de muitos consumidores.

Vale destacar que mesmo sendo uma ação judicial comum em termos técnicos, existem algumas exigências quanto aos órgãos ou pessoas que podem propô-la. A legitimidade para a propositura da Ação Civil Pública é dada no art.5ํㅡㄹ da Lei 7.347/85 e pelo art.82 da Lei 8.078/90, do Código de Defesa do Consumidor. São legitimados:

I. O Ministério Público;

II. A Defensoria Pública;

III. A União, os Estados, o Distrito Federal e os Municípios;

IV. A autarquia, empresa pública, fundação ou sociedade de economia mista;

V. As associações civis constituídas há pelo menos um ano que tenham finalidades institucionais compatíveis com o interesse que se vise a defender; 
VI. As entidades e os órgãos de administração pública, direta ou indireta, ainda que sem personalidade jurídica, especificamente destinados à defesa dos interesses e direitos protegidos por este Código.

Como se verifica, a Ação Civil Pública é um dos meios jurídicos utilizados para a busca de direitos existentes de uma coletividade, mostrando-se também como uma das formas mais específicas e diretas de obtenção de uma proteção dos bens jurídicos de titulares indeterminados, "de forma a condenar em dinheiro ou cumprimento de obrigação de fazer ou não fazer e, ainda de indenizar ou reparar o dano causado." (Art. 3o da Lei 7.347/85).

Portanto, foi no ambiente de tentativa de preservação da Praça Sant'Anna, patrimônio cultural do município de Pirapetinga/MG, contra o risco de descaracterização decorrente do projeto municipal de revitalização, que foi instaurado o Procedimento Preparatório MPMG-0511.10.000011-2 (AÇÃO CIVIL PÚBLICA COM PEDIDO DE TUTELA ANTECIPADA) em razão de carta encaminhada à Promotoria de Justiça da Comarca de Pirapetinga/MG, no dia 09 de setembro de 2010, por José Mauro Pires Silveira, autor deste artigo e organizador do "Manifesto Público em Defesa da Praça Sant'Anna, de 07 de setembro de 2010, cujo texto expressava o repúdio do povo subscrito por 633(seiscentos e trinta e três) cidadãos do município.

Pela análise dos autos do Processo MPMG-0511.10.000011-2 de instauração da Ação Civil Pública movida pelo Ministério Público, constata-se, efetivamente, a necessidade de proteção da Praça Sant'Anna, pois tal decisão fundamentou-se nos seguintes fatos:

$\checkmark$ A existência de uma placa colocada no coreto da praça na ocasião das comemorações do 66ํaniversário do município, reconhecendo a praça como um bem de valor histórico e cultural a ser preservado;

$\checkmark \quad$ A análise de uma Ata Extraordinária do Centro Cultural de Pirapetinga, a qual descreve em detalhes a ameaça consubstanciada no chamado projeto de revitalização da praça;

$\checkmark$ A construção da Igreja Sant'Anna e da praça existente em seu largo decorreu da doação, feita pelos fazendeiros da região, de terrenos à Igreja Católica, encontrando-se nos registros elementos sobre a existência da praça no ano de 1898;

$\checkmark$ A cidade de Pirapetinga cresceu no entorno da Igreja Sant'Anna e da Praça Sant'Anna, tendo sido esta sempre uma importante referência no que tange à identificação das pessoas deste lugar;

$\checkmark$ Em pesquisa realizada pelo sítio da internet da Prefeitura Municipal de Pirapetinga, a praça foi eleita como o local ou monumento que mais traz lembranças da cidade às pessoas, quando essas se encontram fora do município;

$\checkmark$ O Poder Legislativo do Município também se opõe à execução do projeto de reforma da praça;

$\checkmark$ A praça é de relevante importância histórica e cultural para o município de Pirapetinga/MG;

$\checkmark$ Caso o projeto de revitalização apresentado pela Prefeitura Municipal de Pirapetinga (Ofício /GP/nำ276/2010) fosse levado a efeito tal como concebido, causaria a completa desca- 
racterização da mesma, reduzindo significativamente sua área para construção de estacionamento de veículos e retirando o seu caráter de local de convivência dos cidadãos em prol da construção de um parque infantil que ocuparia outra parcela significativa de sua área.

Diante de tal constatação, requereu a promotoria, nos termos do art.12 da Lei ํㅜ 7347/85, a concessão de medida acautelatória, ex limine, determinando ao Réu, o Município de Pirapetinga/MG, representado pelo prefeito municipal, a imediata suspensão do procedimento licitatório para a execução do projeto declarante de revitalização da praça tal como concebido, para que posteriormente fosse realizada a fidedigna restauração do imóvel.

Em 03 de fevereiro de 2010, por decisão judicial, foi concedida a Antecipação de Tutela, obrigando o município a suspender o projeto de revitalização que alterava as características próprias da praça, causando a perda do objeto da ação, no que se refere à preservação do patrimônio histórico e cultural da cidade, ocasionando lesão irreparável do direito. Por último, reitera a decisão:

Finalmente em se tratando de patrimônio imaterial cultural e histórico, deve ser aplicado o princípio de precaução, de modo que a modificação da situação do bem somente ocorra após a certeza de sua viabilidade técnica e jurídica, preservando-se o status quo até essa definição, pelo que é de ser acolhido o pedido antecipatório. [...] Além disso, o periculum in mora ${ }^{1}$ inverso é muito menor, consistente na possível perda temporária de valores do orçamento estadual, para a consecução da reforma na praça, pois é possível resgatar a dotação orçamentária, o que não se pode dizer de um patrimônio cultural e histórico, cujo valor está exatamente na manutenção da situação. Diante do exposto, e considerando o que mais dos autos consta, CONCEDO A ANTECIPAÇÃO DE TUTELA para determinar que o Município de Pirapetinga, representado pelo prefeito municipal, se abstenha de promover ou autorizar - a qualquer título - projetos e obras relativos à alteração da Praça Sant'Anna, até ulterior decisão judicial, sob pena de multa diária de $\mathrm{R} \$ 10.000,00$ (dez mil reais), sem prejuízo de eventual responsabilização penal e pela prática de improbidade administrativa (SILVEIRA, 2017, p. 23).

Nesse contexto, conclui-se que a proteção da Praça Sant'Anna se dá através do ajuizamento da Ação Civil Pública pelo Ministério Público, com a necessidade da intervenção do Poder Judiciário como linha de defesa da integridade do patrimônio cultural do município de Pirapetinga/MG.

\section{ALGUMAS CONSIDERAÇÕES SOBRE PATRIMONIAL CULTURAL}

Atualmente não são poucos os conceitos a respeito do patrimônio cultural. Esse tema passou a ter grande importância nas esferas públicas e privadas a partir das quatro últimas décadas, inclusive com a Constituição de 1988, expresso no art.216:

Art. 216. Constituem patrimônio cultural brasileiro os bens de natureza material e imaterial, tomados individualmente ou em conjunto, portadores de referência à identidade, à ação, à memória dos diferentes grupos formadores da sociedade brasileira, nos quais se incluem:

\footnotetext{
1 Periculum in mora - Receio de dano irreparável ou de difícil reparação. O periculum in mora é expressão latina que quer significar perigo da demora (na prestação da tutela jurisdicional). Noutro falar, é "locução latina que designa uma situação de fato, caracterizada pela iminência de um dano, em face da demora de uma providência que o impeça" (GOMES, 2009). 
I. As formas de expressão;

II. Os modos de criar, fazer e viver;

III. As criações científicas, artísticas e tecnológicas;

IV. As obras, objetos, documentos, edificações e demais espaços destinados às manifestações artístico-culturais;

V. Os conjuntos urbanos e sítios de valor histórico, paisagístico, artístico, arqueológico, paleontológico, ecológico e científico.

Segue no $\$ 1^{\circ} \mathrm{O}$ poder público, com a colaboração da comunidade, promoverá e protegerá o patrimônio cultural brasileiro, por meio de inventários, registros, preservação, vigilância, tombamento e desapropriação, e de outras formas de acautelamento e preservação.

Por essa conceituação, o patrimônio cultural é formado pelos bens materiais e imateriais, singulares ou coletivos, intimamente relacionados à identidade, à memória, à cultura ou ao passado de uma coletividade. Ele se refere a um valor para as pessoas, grupos ou nações. É algo que nos remete para à ideia de herança ou legado, que serve como um referencial para nossa identidade individual e de grupo.

O conjunto de bens culturais pode ser dividido em duas categorias: a primeira, dos tangíveis (móveis e imóveis); e a segunda, dos intangíveis (imateriais). Os bens imóveis são os monumentos, edifícios, casarões, lugares arqueológicos, conjuntos históricos, paisagísticos, e elementos naturais com arvores, grutas, lagos, montanhas e outros que podem encarnar impotentes tradições culturais. Os bens móveis que são representados por diversos objetos relacionados à arte, à religião, ao trabalho, aos livros e aos documentos, aos achados arqueológicos, às coleções e aos acervos museológicos, e às diversificadas fontes documentais e as de arquivos; os intangíveis, que por sua vez tem uma existência imaterial, são as crenças, costumes, fazeres, saberes, ideias, danças, cantigas, cantorias, tradição oral, entre diversas manifestações que constituem as identidades e as memórias coletivas (FIGUEIRA; MIRANDA, 2012, p.38). (Grifos do autor)

Os bens culturais passam a ter uma importância muito grande para a vida social porque testemunham a cultura humana, constituindo-se como um elo identificador do passado e também do presente, enchendo de significados os espaços e os lugares.

No pioneiro trabalho do historiador francês Pierre Nora, "lugares de memória", tem-se uma compreensão maior de espaço e tempo na construção da identidade de determinados grupos da sociedade urbana. "O lugar de memória é um lugar duplo; um lugar de excesso, fechado sobre si mesmo, fechado sobre sua identidade, e recolhido sobre seu nome, mas constantemente aberto sobre a extensão de suas significações" (NORA, 1993, p. 21). Fica perceptível, dessa maneira, que esses "lugares de memória" fazem parte da existência coletiva evidenciada em diversos tempos históricos e que se expressam por um sentimento de referência e identificação grupal. São eles que definem os grupos de um determinado lugar, criando o sentimento de pertencimento à vida social. Como bem salienta Paulo Cesar Tomaz:

[...] essa memória pode ser despertada através de lugares e edificações, e de monumentos que, em sua materialidade, são capazes de rememorar a forma de vida daqueles que no passado deles se utilizaram. Cada edificação, portanto, carrega em si não apenas o material de que é composto, mas toda uma gama de significados e vivências ali experimentados (TOMAZ, 2010, p. 2). 
Ou seja, os típicos "lugares de memória" são os próprios ambientes, as praças, igrejas, os monumentos, edifícios públicos e privados de uma localidade, uma bandeira, um hino nacional, uma árvore centenária, uma escola, uma biblioteca, enfim, em qualquer lugar onde se cruzam memórias pessoais, familiares e de grupo.

Maurice Halbwachs, outro investigador da memória coletiva, afirma que: "[...] nossas lembranças permanecem coletivas, e elas nos são lembradas pelos outros, mesmo que se trate de acontecimentos em que só nós estivemos envolvidos, e com objetos que só nós vimos" (HALBWACHS, 2004, p.30). Assim, pelas lembranças cristalizadas em certos lugares numa história de vida individual ou coletiva é que se solidifica a memória, passando a fazer parte da própria essência da pessoa e do grupo, não tendo como dissociar-se do tempo passado e do presente. São como espelhos nos quais, simbolicamente, um grupo social ou um povo se "reconhece" e se "identifica", mesmo que de maneira fragmentada.

Ao recorrermos à memória para nos lembrarmos dos espaços ou dos eventos, iremos nos apoiar nas lembranças que tínhamos desses locais e acontecimentos. Isso porque eles vão sendo construídos e guardados em nossos arquivos de memória, com significados e valores pertencentes somente a nós e ao grupo a que pertencemos. E, como os lugares se constituem de edificações e de monumentos que, em sua materialidade, são capazes de reconstruir as lembranças de um outro tempo no tempo presente, eles passam a ser considerados como patrimônio cultural de um determinado grupo e por ser de muito valor e deixados para as futuras gerações, é que se justifica a sua preservação.

Para Ecléa Bosi, "As lembranças se apoiam nas pedras da cidade. Se o espaço, para Merleau-Ponty, é capaz de exprimir a condição do ser no mundo, a memória escolhe lugares privilegiados de onde retira sua seiva" (BOSI, 2003, p. 4). Então, tem a memória a capacidade de nos ligar às coisas, aos objetos, aos lugares, de nos dar significados para os espaços em que vivemos, servindo-se como um elemento de identificação de um grupo social.

É dentro desse contexto que se insere a Praça Sant'Anna, objeto desse artigo, que tanto suscitou esforços no sentido de sua preservação como patrimônio cultural do município de Pirapetinga/MG. A partir de seu estudo, é possível dimensionar o seu valor enquanto um bem cultural imprescindível para a coletividade a que pertence.

\section{PRAÇA SAN'ANNA: MARCO CENTRAL DA ORIGEM DE PIRAPETINGA}

Analisando-se a história de Pirapetinga, município localizado na região Sul da zona da Mata de Minas Gerais, é possível verificar que foi com a igreja e a praça que por volta de 1850 surgiu à cidade, cujo núcleo se denominava Sant'Anna do Pirapetinga.

A partir desse espaço, que se deu a construção de casas, ruas e bairros da cidade. A cada década vivida, centenas de obras foram e vêm transformando o espaço natural e geográfico da cidade, fazendo crescer a vida urbana, sem, contudo, fazer com que se perca a vida interiorana dessa população.

Assim, com tantas construções por todos os lados da cidade, a igreja e a praça ainda permanecem esculpidas pelas mãos dos seus antepassados, simbolizando para os pirapetinguenses o berço da sua história. 
Dados revelam que o nome "Praça Sant'Anna" é em razão da sua ligação com a Igreja Matriz de Sant'Anna, ou seja, ambas são pertencentes a um mesmo conjunto arquitetônico local, não se conseguindo visualizar uma separada da outra. A importância histórica da edificação da Igreja Matriz de Sant'Anna (1885) abrange também o seu entorno, destacando a Praça Sant'Anna, na qual está localizada a referida igreja. Pela ilustração da Figura 1 pode-se identificar esse elemento aglutinador:

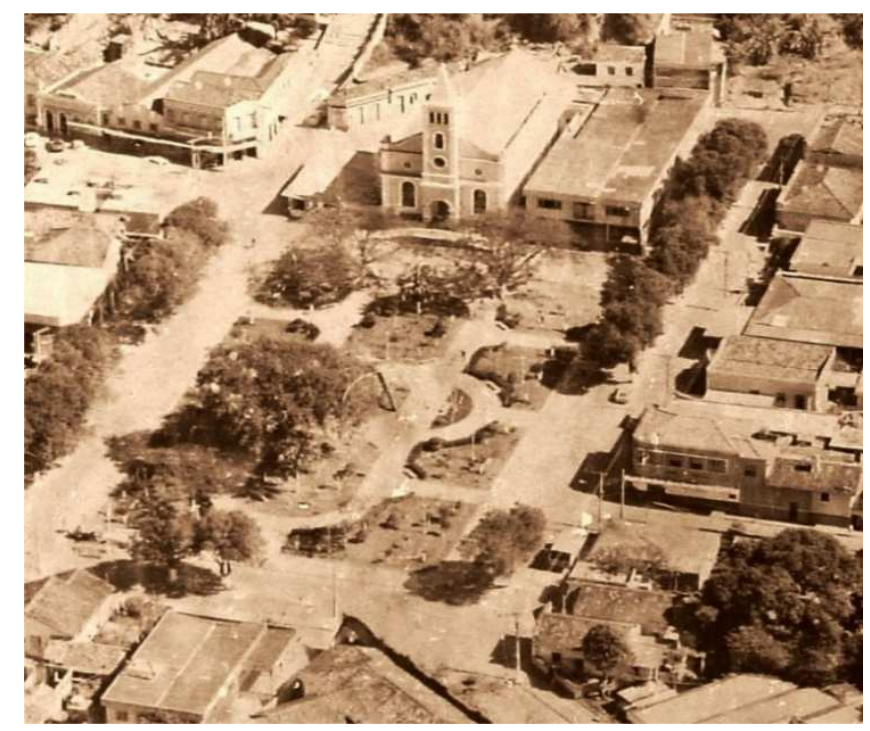

Figura 1 - Imagem aérea da Praça Sant' Anna e da Igreja Sant'Anna.

Fonte: Casa de Cultura Prof ${ }^{a}$ Geralda Bifano Jubileu - Pirapetinga/MG.

Para Flavio de Lemos Carsalade (2010, p.86), "a arquitetura cria lugares e referência a vida urbana, a cidade de cada um e a cidade de todos. Ela assim o faz através da criação de marcos referenciais e de paisagens urbanas particulares" E acrescenta: "[...] o patrimônio se apresenta como elo que gera os lugares urbanos e que liga o cidadão à sua cidade."

Vê-se, portanto, que há uma relação de significados entre a arquitetura e a cidade. Ao construir as cidades, por sua forma e conteúdo, a arquitetura tem o papel fundamental de estabelecer as inter-relações do homem com seu meio, ou seja, juntamente com o aspecto físico e ambiental, criamse os seus referenciais culturais. Assim, a sensibilidade do lugar fica demonstrada com a força da Arquitetura, como ligação entre a natureza, a cultura e as histórias locais.

Cumpre lembrar aqui, a pesquisa realizada pela Prefeitura Municipal de Pirapetinga através do seu site oficial, na qual se perguntava aos internautas qual era o local ou monumento que mais trazia lembranças da cidade às pessoas quando essas se encontravam fora do município, tendo sido a praça, a igreja e a pedra bonita os três monumentos mais votados. Dessa forma, afirma Kevin Lynch,

[...] não percebemos a cidade como um todo, mas partes dela com as quais o cidadão se identifica ou estabelece algum vínculo. Esta percepção fragmentada permite o surgimento de marcos, cartões postais, elementos que se destacam física e afetivamente do conjunto da cidade, formando uma identidade (DUARTE, 2011, p. 905). 
Não há dúvida de que a Praça Sant'Anna é um espaço coletivo, agregador e socializador. Historicamente, ela tem desempenhado várias funções de interesse público, como a ecológica, social, estética, educativa e psicológica. Nela também se desenvolve o sentido de passagem, de festas, de espaço de manifestações, de lazer, de contemplação e de religiosidade.

Aqui a arquitetura assume lugar de destaque, numa verdadeira relação simbólica com o grupo social ao longo dos anos, estabelecendo-se relações de afeto, de pertencimento, de memórias e de identidade. É um espaço que leva os habitantes da cidade a refletirem e a tomarem contatos com outros períodos da história, constituindo-se em um dos bens culturais a serem preservados.

Verifica-se que o projeto arquitetônico que deu origem à Praça Sant'Anna, denominado de "Projeto Público de Pirapetinga", elaborado pelo técnico Júlio R. Steinmetz, em 1942, na administração do 1ำ prefeito do município, José Ferreira de Souza, em substituição à Praça Cel. Ferraz, permanece com o seu traçado original até os dias atuais, sem nenhuma redução de sua área física, apenas sendo substituído o coreto (1984) por outro (embora, o projeto indicasse uma fonte luminosa, no centro) e retirados dois canteiros menores localizados ao lado do mesmo, ficando garantida a sua preservação histórico-patrimonial. Pela Figura 2, tem-se a imagem do projeto da Praça Sant'Anna datado de 1942.

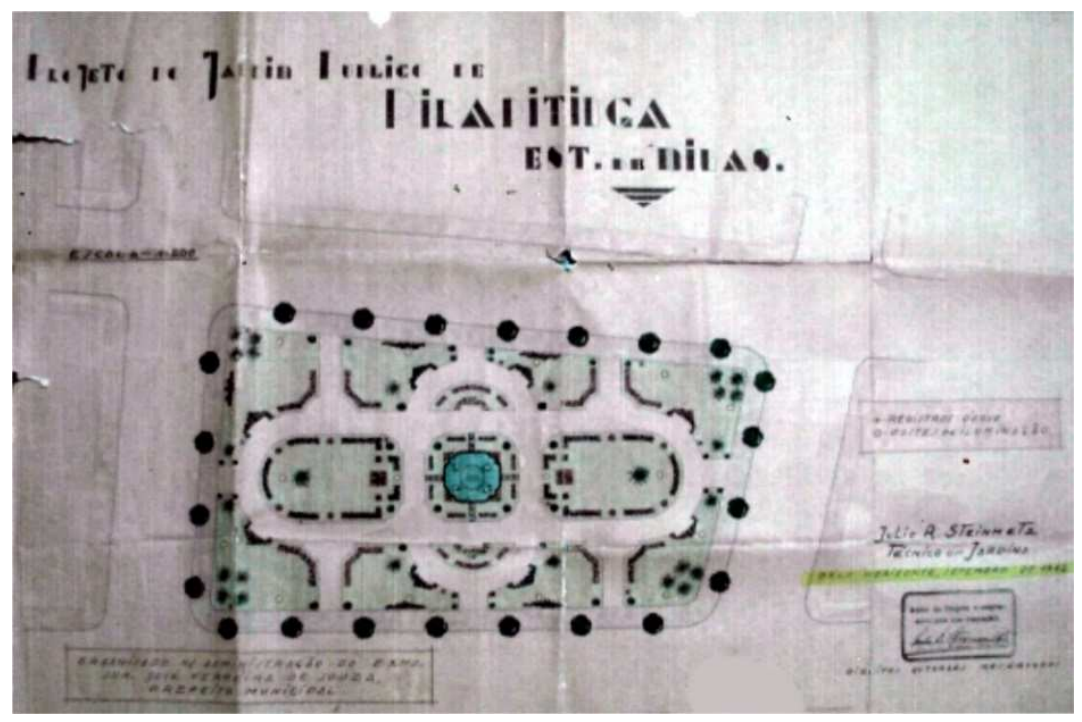

Figura 2 - Imagem do projeto da Praça Sant' Anna, datado de 1942. Fonte: MPMG-0511.10.000011-2, p.899.

A Praça Sant'Anna é evidentemente um espaço público, de convívio social, caracterizado por elementos físicos, ambientais, sociais, religiosos e culturais, que faz parte da história de Pirapetinga, guardando em si uma estreita relação sociológica com os seus munícipes, numa conexão que ajuda determinar os valores do povo. Como exemplo, tem-se o agregado social que se faz em seu entorno. Durante todos os dias pode-se perceber o valor que as pessoas atribuem ao passeio permanente em volta da praça, numa trajetória e ritmo que se constitui como um processo fundamental de equilíbrio sociocultural.

Ainda que a praça tenha passado por transformações nas últimas décadas como ressaltou a Prefeitura Municipal de Pirapetinga para justificar a execução de um novo projeto de reforma, a mesma reconhece que dar "voltinhas na praça" é um patrimônio da cultura imaterial dos moradores da 
cidade, conforme encontra-se no Processo MPMG-0511.10.000011-2, destacando a importância desse bem cultural para a memória e a identidade dos munícipes:

\begin{abstract}
Um dos maiores patrimônios culturais da nossa cidade, está sim relacionado à Praça Sant'Anna, mas nós Pirapetinguenses quase não percebemos, pois está no nosso subconsciente... porém, um visitante que resolver conhecer a Praça Sant'Anna à noite ou principalmente em um final de semana ou festa, logo percebe... Às vezes acha engraçado, às vezes acha estranho, às vezes zomba, mas acaba não resistindo e assim como todos nós já fizemos muitas vezes em nossas vidas, acabam também por dar 1,2, 10, inúmeras "voltinhas na praça". Sem dúvida alguma, dar voltinhas na Praça Sant'Anna é um patrimônio cultural de Pirapetinga (SILVEIRA, 2017, p. 82-83).
\end{abstract}

Portanto, a Praça Sant'Anna, localizada no centro da cidade, é o espaço por excelência de Pirapetinga, local de encontro e de lazer de toda à comunidade. É um espaço onde os seus habitantes se reúnem para resgatar parte da sua história; é um local cheio de significados, com grande conteúdo simbólico; representa o espaço da memória viva local.

Ao ser reconhecida pela Ação Civil Pública como um referencial cultural e histórico de fundamental importância para o município de Pirapetinga/MG, a Praça Sant'Anna foi protegida e preservada, já que qualquer intervenção que alterasse a sua estrutura e o seu uso, de forma a descaracterizála culturalmente, significaria do ponto de vista histórico para os habitantes da cidade, a perda da cidadania, da memória coletiva, do senso de pertencimento e da qualidade de vida.

Diante do caráter preventivo da ação, foi proposto pela Promotoria Estadual de Defesa do Patrimônio Cultural e Turístico ao Conselho Municipal de Patrimônio Cultural de Pirapetinga, o tombamento da Praça Sant'Anna e da Igreja Sant'Anna, tendo em vista que, dessa forma, ambas estariam protegidas e reconhecidas pelo poder público como patrimônio cultural da cidade. Assim, no dia 28 de maio de 2014, através do decreto oㅡ 21/2014 (SILVEIRA, 2017, p. 84) por ato do Poder Executivo, ficou declarado o tombamento definitivo da Praça Sant Anna como patrimônio cultural do município, tendo em vista o seu valor histórico para a população pirapetinguense.

\title{
CONSIDERAÇÕES FINAIS
}

A Praça Sant'Anna entendida como o espaço reconhecido, identificado, valorado pelas pessoas e delimitado fisicamente por uma arquitetura imemorável, corria sério risco de ser destruída por um projeto de reforma do poder público municipal, implicando na perda total dos seus elementos históricos e culturais.

Nesse particular, valendo-se de um hábil instrumento processual de defesa dos interesses difusos, a Ação Civil Pública de propositura do Ministério Público, foi, indiscutivelmente, a principal responsável pela obtenção da proteção satisfatória dos bens jurídicos de titulares indeterminados, possibilitando ao cidadão pirapetinguense a defesa imediata da praça sob a tutela de condenar em obrigação de fazer ou não fazer e, ainda, de indenizar ou reparar o dano causado.

Defender o patrimônio cultural de um determinado lugar é uma necessidade primordial para se manter viva a memória e a identidade de um povo. Mas, como nem sempre o poder público local tem a preocupação e o interesse pela preservação dos bens culturais da sociedade devido à falta de compreensão e de sensibilidade, concluiu-se, que a sociedade em geral tem um papel fundamental 
no processo de preservação dos seus próprios bens patrimoniais, cabendo a mesma procurar o Ministério Público quando houver possibilidade da ameaça, reparação ou perda do patrimônio local, para que ele possa agir por meio da via judicial usando os instrumentos legais que dispõe: a ação civil pública, ação popular e ações coletivas.

Dadas às discussões acerca do objeto, torna-se irrefutável a afirmação de que a Praça Sant'Anna tem um significado imensurável para o município de Pirapetinga/MG, destacando-se por ser o local onde se deu a origem da cidade e, por outro lado, por ser lugar de preservação das memórias coletivas e das histórias do povo. E como tal, é considerada o coração da cidade.

\section{REFERÊNCIAS}

BERUTTI, Flávio; MARQUES, Adhemar. Ensinar e Aprender História. Belo Horizonte: RHJ, 2009.

BITTENCOURT, Circe Maria Fernandes. Ensino de História: fundamentos e métodos. São Paulo: Cortez, 2009.

BOSI, Eclea. Memória da cidade: lembranças paulistanas. In: Estudos Avançados, vol.17, n.47, São Paulo Jan./Apr, 2003. Disponível em http://www.scielo.br/scielo.php< Acesso em: 19 jun 2015.

BRASIL. Tribunal de Justiça de Minas Gerais. Comarca de Pirapetinga. Processo. $n^{-}$ 0511.10.000011-2. Ação Civil Pública. 2010, p.2-5.

BRASIL. Código de Processo Civil. São Paulo: Edições Vértice, 2005. Série Legislação AcadêmicoForense.

CARSALADE, Flávio de Lemos. Área Central: um olhar a partir do patrimônio cultural. In: Locus: Revista de história, Juiz de Fora, v.16, n.2, p.79-92, 2010, p.86.

DUARTE, Neise Mendes. Promotoria Estadual de Defesa do Patrimônio Cultural e Artístico de Minas Gerais. Nota Técnica n.48/2011.PAAF № 0024.10.005542-5, p.905. In: Proc. no MPMG0511.10.000011-2; Comarca de Pirapetinga.

FERNANDES, Juliano Gianechini. Breves considerações sobre Ação Civil Pública no Processo do Trabalho Brasileiro. Processos Coletivos, Porto Alegre, vol. 4, n. 2, 01 abr. 2013. Disponível em: http://www.processoscoletivos.net/1211-breves-consideracoes-sobre-acao-civil-publicanoprocesso-do-trabalho-brasileiro - Acesso em: 09-Jun-2015

FIGUEIRA, Cristina Aparecida Reis. GIOIA, Lílian de Cássia Miranda de. Educação patrimonial no ensino de história nos anos finais do ensino fundamental: Conceitos e práticas. São Paulo: Edições SM, 2012, p. 38.

GOMES, Luiz Flávio. Disponível em: http://lfg.jusbrasil.com.br/noticias/475942/que-se-entende-porpericulum-in-mora-inverso, 2009< Acesso em : 18 de junho de 2015.

HALBWACHS, Maurício. Memória Coletiva. São Paulo: Editora Centauro, 2004, p.30.

IBGE. www.biblioteca.ibge.gov.br

MANCUSO, Rodolfo de Camargo. Ação Civil Pública: em defesa do meio ambiente, do patrimônio cultural e dos consumidores - Lei 7.347/85 e legislação complementar. São Paulo: Editora Revista dos Tribunais, 2009.

NORA, Pierre. Entre memória e história: a problemática dos lugares. In: Projeto História, São Paulo, n.10, dez. 1993 Disponível em: http://revistas.pucsp.br/index.php/< Acesso em 18 jun 2015. 
RAMALHO, Paulina Onofre. Lugar de Memória: o plano urbanístico de Boa Vista/Roraima. 2012. 99 f. Dissertação (Mestrado em Preservação do Patrimônio Cultural) - Iphan, Rio de Janeiro, 2012. Disponível http://portal.iphan.gov.br/pagina/detalhes/459.< Acesso em 19 jun 2015.

SILVA, René Marc da Costa. Cultura Popular e Educação: Salto para o futuro. Brasília: Ministério da Educação, 2008.

SILVEIRA, José Mauro Pires. Ação Civil Pública - em defesa do Patrimônio Cultural Praça Sant'Anna. 1. Ed. Curitiba, PR: CRV, 2017.

TOMAZ, Paulo César. A preservação do patrimônio cultural e sua trajetória no Brasil. In: Revista de História e Estudos Culturais.v.7, n.2, Ano VII, ISSN 1807.6971. Disponível em: www.revistafenix.pro.br >. Acesso em 11 jun. 2015. 